\title{
VIABILIDADE DE QUEIMA DE RESÍDUO DE MAMONA: UM PROBLEMA INDUSTRIAL VIRA METODOLOGIA DE ENSINO E SOLUÇÃO ENERGÉTICA SUSTENTÁVEL
}

Cleidson Carneiro Guimarães, Kate Lirane de Araújo Costa, Romana Rebeca Barros

Universidade Federal do Recôncavo da Bahia

<cleidsonguimaraes@gmail.com>,<lirane.kl@hotmail.com>,<romanarebeca@ hotmail.com>

DOI: $10.21439 /$ conexoes.v9i4.942

\begin{abstract}
Resumo. Neste trabalho os estudantes do curso Técnico em Química, do SENAI de Feira de Santana, receberam o desafio de encontrar um destino ambientalmente sustentável para o resíduo (borra) gerado no processo de refino do óleo vegetal da empresa Bioóleo Industrial e Comercial S.A por meio da metodologia TheoPrax. A borra gerada no tratamento do efluente tem sido um dos maiores problemas vivenciados pela empresa, pois a falta de espaço físico para disposição da mesma ocasiona redução de espaço para a produção. Foram realizados ensaios como composição química, teor de umidade, poder calorífico, densidade, matéria mineral e teor de ácidos graxos. Os ensaios foram realizados no laboratório da empresa de forma que o enfrentamento do problema, pelos estudantes, caracterizou-se como um problema real a ser resolvido no local de trabalho do técnico em Química. A partir dos dados e à luz do referencial teórico, foi avaliado o potencial do resíduo para produzir energia térmica e melhorar o fluxo de trabalho na Estação de Tratamento de Efluentes (ETE). Os resultados demonstraram a viabilidade de utilização do resíduo como combustível industrial, reduzindo as despesas com cavaco de eucalipto. Além disso, a metodologia de inserção do estudante em problemas reais aproxima o estudante do mundo do trabalho e motiva a construir soluções pela interação entre o conhecimento acadêmico e o cotidiano industrial.
\end{abstract}

Palavras-chaves: Ensino-aprendizagem, resíduo industrial e TheoPrax.

\begin{abstract}
In this work the students of the Technical Course in Chemistry, the Feira de Santana SENAI, given the challenge of finding an environmentally sustainable destination for the waste (sludge) generated in the refining process of vegetable oil company Industrial Bioóleo e Comercial SA by TheoPrax methodology. The sludge generated in the treatment of effluent has been one of the biggest problems experienced by the company, since the lack of physical space for provision of the same causes space reduction for production. assays were performed as chemical composition, moisture content, calorific value, density, mineral matter and fatty acid content. The tests were performed in the laboratory of fashion company that fight the problem, the students, was characterized as a real problem to be solved in the technical workplace in Chemistry. From the data and in the light of the theoretical framework, the residue of the potential has been evaluated to produce thermal energy and improve workflow in the Effluent Treatment Plant (WWTP). The results demonstrated the feasibility of using waste as industrial fuel, reducing the cost of eucalyptus chips. In addition, the student's integration methodology on real problems approaching the student world of work and motivates them to build solutions for interaction between academic knowledge and industrial environment.
\end{abstract}

Keywords: Learning-teaching, industrial waste and TheoPrax.

\section{INTRODUÇÃO}

Um desafio constante do docente é a busca de construção de significado ao saber que ensina. Não faz sentido, principalmente nos cursos profissionalizantes, adotar metodologias de aprendizagem baseada apenas na aula expositiva. Conforme apontou Freire (1996), 

SOLUÇÃO ENERGÉTICA SUSTENTÁVEL

não é possível transferir saberes da estrutura cognitiva de um ser humano para o outro, os humanos constroem saberes em comunhão. Além disso, a vida profissional exige muito mais do que memorizar informações. É fundamental utilizar o conhecimento para resolver os problemas cotidianos da vida profissional dentro das empresas onde trabalha.

Nesse contexto, é fundamental que o Ensino Profissionalizante adote metodologias de ensino que incorporem problemas reais do mundo do trabalho como estratégia metodológica de construção de saberes e competências. Desde 2008 o Serviço Nacional de Aprendizagem Industrial (SENAI) adotou a metodologia TheoPrax. Esta metodologia foi desenvolvida no Instituto Fraunhofer, na Alemanha, e consiste na inserção do educando em situações problemas reais oriundos da indústria, na perspectiva de aliar teoria (THEO) e prática (PRAX). Segundo Krause e Eyerer (2008), TheoPrax é uma metodologia que associa ensino e aprendizagem, em torno de um problema real oriundo da integração escola-empresa. A escola entra em contato com as indústrias e empresas da região, que apresentam problemas, e estes precisam ser resolvidos pelos estudantes, em forma de projeto. É realizada uma relação de proposta-contratação entre empresa (contratante) e escola (contratada), garantindo assim o caráter real do projeto. Os alunos são divididos em equipes e cada equipe recebe um projeto diferente, para ser realizado em um período definido de tempo. O passo seguinte é a pesquisa e planejamento do projeto. Ao final do período programado, os alunos apresentam a solução ao problema e um relatório final para a escola e para a contratante, que pode ainda incluir a simulação e/ou apresentação de um protótipo.

Nesse contexto, uma equipe do curso Técnico em Química (do SENAI de Feira de Santana), recebeu o desafio de encontrar uma solução para o resíduo (aqui denominado por borra) gerado no processo de tratamento de efluente da empresa Bioóleo - Industrial e Comercial S.A, situada em Feira de Santana. Esta empresa processa diversas oleaginosas tais como: mamona em bagas e girassol. Além de processar óleos brutos, de terceiros, de algodão e de soja degomado. As sementes oleaginosas sofrem extração mecânica, a quente, para retirar o óleo bruto e posterior refino. Os produtos finais gerados pela Bioóleo são: óleo de mamona refinado, óleo de algodão semi-refinado, óleo de soja semirefinado e óleo de girassol semi-refinado. Do processo de esmagamento, refino e semi-refino são gerados efluentes contaminados aos quais são conduzidos até a Estação de Tratamento de Efluentes (ETE) que retira a parte sólida (dissolvida ou em suspensão) do solvente (água). Após este tratamento, origina uma borra a qual fica depositada no pátio da empresa até o transporte para outra empresa que dá o destino final. Todavia, esta alternativa traz custos à Bioóleo e não agrega valor ao material e não estimula ações sustentáveis e de logística reversa.

A sustentabilidade consiste no entendimento de que o mundo e seus habitantes formam um sistema único. Adotar ações sustentáveis é fundamental em todas as cadeias produtivas. Portanto, visa o desenvolvimento humano para diminuir as desigualdades sociais e, ao mesmo tempo, evitar o esgotamento dos recursos naturais e os sistemas biológicos do planeta (SPENCE; MULLIGAN, 1995). Nesse sentido, preservar os recursos naturais é, também, pensar inclusive nas futuras gerações e na manutenção da cadeia produtiva.

Diante do custo, ausência de espaço físico de trabalho na ETE e necessidade (da Bioóleo) de estimular ações sustentáveis, desenvolveu-se um projeto para o aproveitamento do resíduo orgânico (Borra) para obter energia térmica. Para isto, o resíduo foi coletado na empresa e caracterizado com base nas principais propriedades, conforme Silva e Morais (2008), físico-químicas do material: composição, poder calorífico (superior e inferior), densidade, umidade e teor de cinzas.

$\mathrm{O}$ poder calorífico indica a quantidade de energia liberada após a combustão completa de um combustível por unidade de massa, divide-se em superior e inferior. O Poder Calorífico Superior (PCS) é aquele onde a combustão se efetua a volume constante e no qual a água formada durante a combustão é condensada resultando na recuperação do calor derivado desta condensação. Já o Poder Calorífico Inferior (PCI) é a energia efetivamente disponível, por unidade de massa de combustível, após as perdas devido à absorção de energia pela evaporação da água (BRIANE; CAETANO; DOAT, 1985; DUARTE JUNIOR, 2014; GARCIA, 2002; JARA, 1989 apud QUIRINO, 2005; SILVA; MORAIS, 2013).

O teor de umidade do material e a densidade são fatores que interferem no aproveitamento energético, pois tanto maior o teor de água, menor será o calor liberado durante a combustão. Já a densidade interfere no tempo de combustão, materiais com densidade muito alta apresentam, geralmente, maior dificuldade de iniciar a combustão, enquanto densidade baixa implica em queima rápida e menor quantidade de energia por unidade de volume. A densidade ideal para a queima em caldeira industrial varia de 0,65 a $0,80 \mathrm{~g} / \mathrm{cm} 3$ (VALE et al., 2011). Em relação à madeira, o teor máximo de umidade que permite a queima varia em torno de $65 \%$ a 70\% em base úmida (QUIRINO et al. 2005). 

SOLUÇÃO ENERGÉTICA SUSTENTÁVEL

A combustão de um material começa pelos voláteis que, geralmente, exigem menor teor de oxigênio resultando em combustão completa. Logo, pode-se destacar os ácidos graxos como os materiais mais voláteis dentre os constituintes da borra. Assim sendo, sua determinação será imprescindível e constitui parte das análises de caracterização do material.

Embora a o conceito de competência seja multissêmico, adota-se a compreensão de competência como "uma capacidade de agir eficazmente em um determinado tipo de situação, apoiada em conhecimentos, mas sem limitar-se a eles" (PERRENOUD, 1999, p. 7). Reitera-se a compreensão que o ensino técnico deve estar além das tradicionais aulas expositivas, deve educar para o agir competente. E isso significa saber delimitar o problema a enfrentar, reunir os saberes e as ferramentas para superar e criar novos saberes. "Um treinador não dá muitas aulas. Coloca o aprendiz em situações que o obrigam a alcançar uma meta, a resolver problemas, a tomar decisões" (PERRENOUD, 1999, p. 57). Essa compreensão orientou as ações desse trabalho.

$\mathrm{Na}$ perspectiva de ir além da educação bancária (FREIRE, 1996), esse trabalho, não apenas propõe, mas pôs em prática ações que exigiram do discente a operacionalização de conceitos e construção de saberes. Enquanto, o docente precisa estar além do ministrar aulas expositivas, mas estar disposto e apto a mediar a resolução do problema e aquisição significativa dos conceitos.

\section{MATERIAIS E MÉTODOS}

Esse trabalho apresenta duas vertentes. Numa delas, relata a experiência de construção de saberes por meio do enfrentamento de um problema real oriundo da empresa Bioóleo: encontrar uma solução viável, econômica e ambiental, para o resíduo gerado pelo tratamento do efluente da extração de óleos vegetais. Na outra, apresenta a caracterização de um resíduo industrial gerado pela ETE de uma empresa que produz óleos vegetais.

Antes de enfrentar o problema e realizar os ensaios necessários para a caracterização físico-química do material (no laboratório da empresa), foi necessário realizar pesquisas de referenciais teóricos no intuito de construir o arcabouço teórico necessário ao agir competente no enfrentamento do problema. Após isso, a equipe foi orientada a conhecer a norma ISO 17025 (2005) que aponta os requisitos gerais para ensaios e calibração.

Os ensaios realizados na empresa foram: densidade, teor de cinzas, ácidos graxos totais (AGT) e Umidade. O poder calorífico foi realizado por laboratório externo - Centro de Qualidade Analítica - CQA. O laudo técnico de composição química da borra seca foi realizado pelo Centro de Pesquisas e Desenvolvimento Leopoldo
A. Miguez de Mello (CENPES) da PETROBRAS. Estes dois últimos ensaios não foram executados pelos estudantes porque não fazem parte da rotina da empresa. Entretanto, a análise dos resultados (que é uma competência fundamental ao Técnico em Química) foi efetuada pelos discentes, sob a mediação docente.

A análise de umidade foi realizada baseando-se na norma American Oil Chemists' Society (AOCS) Ba 2a38 (2009). Empregou uma amostra de cinco gramas para aquecer a uma temperatura de $130^{\circ} \mathrm{C}$ durante duas horas. Após aquecimento, a amostra foi resfriada em dessecador por trinta minutos. $\mathrm{O}$ resultado da umidade é a relação da massa seca pela massa total da amostra em percentual. Já a avaliação da densidade baseou-se na norma NBR 11941 (2003). Foram utilizados dez gramas da amostra da borra em pequenas bolas imersas numa proveta, contendo cinquenta mililitros de água deionizada. Com o volume de água estabilizado, mediu-se o volume deslocado pela massa.

A avaliação do teor de cinzas foi realizada com uma amostra, de massa 2 gramas, incinerada em mufla, a uma temperatura de $600^{\circ} \mathrm{C}$, durante duas horas. O resfriamento foi realizado em dessecador, por meia hora. Os resultados da análise de cinzas baseiam-se na relação da massa da amostra incinerada pela massa da amostra natural em percentual.

O procedimento para a análise de ácidos graxos totais (AGT) utilizou uma amostra de massa igual a dez gramas diluída em água destilada e fervida sob agitação. Posteriormente, acidificada e fervida de forma que todo sabão seja fundido. Drenada a fase aquosa, a fase oleosa é lavada, com solvente orgânico, até sua purificação. Por diferença de peso a parte graxa é quantificada em percentual. O resultado de AGT é a relação entre os ácidos graxos totais e a amostra in natura, em percentual.

Após a coleta de dados, os referenciais (discutidos no início do trabalho) foram retomados para discutir os dados e produzir o artigo. Em seguida, os resultados foram apresentados aos colegas da turma do Curso Técnico em Química do SENAI de Feira de Santana e, por fim, aos diretores da empresa.

\section{RESULTADOS E DISCUSSÃO}

Neste trabalho, será enfatizado o poder calorífico inferior, pois este aponta a energia mínima liberada na combustão, destarte, se há viabilidade com o poder calorífico inferior (PCI), então haverá com o superior. Tal qual destaca Garcia (2002), o que as empresas mais utilizam, normalmente, é o PCI, "uma vez que, na maioria dos processos industriais, os gases de combustão são liberados a temperaturas altas onde a água neles contida 
se encontra na fase gasosa" (GARCIA, 2002, p.158).

De forma similar, a caldeira da empresa não aproveita o calor perdido pela evaporação da água, logo o PCI foi avaliado com ênfase neste trabalho.

\subsection{Teor de Carbono}

A composição química da borra seca aponta um teor de carbono de $23,6 \%$. Este valor sinaliza para a possibilidade de queima do material, pois este teor de carbono é superior ao valor médio da madeira $(20,73 \%)$ e da casca de madeira $(25,19 \%)$, segundo Vale, Brasil e Leão (2014).

\subsection{Umidade}

Na geração de energia a partir da biomassa, um parâmetro que deve ser controlado é o teor de umidade uma vez que, quanto menor o teor de umidade maior será a produção de calor por unidade de massa (Vale et al., 2000).

Durante o estudo, foram realizados testes quanto ao teor de umidade no resíduo gerado do processo fabril da Bioóleo, oriundo do refino de óleo vegetal. Os resultados estão apresentados na Tabela 1

Tabela 1: Resultados da Análise de Umidade. Fonte: autores.

\begin{tabular}{ccc}
\hline $\begin{array}{c}\text { Umidade } \\
\mathbf{( \% )}\end{array}$ & $\begin{array}{c}\text { Média } \\
\mathbf{( \% )}\end{array}$ & $\begin{array}{c}\text { Desvio } \\
\text { Padrão }\end{array}$ \\
\hline 65,36 & & \\
63,80 & & \\
66,18 & & \\
66,09 & 64,93 & 1,27 \\
65,14 & & \\
\hline 63,03 & & \\
\hline
\end{tabular}

Os resultados obtidos, embora elevados, mostraram a viabilidade de uso deste material para queima em caldeiras, pois, a média das análises registra um valor menor ao máximo tolerável. Segundo Quirino et al. (2005), o teor de umidade de um material a ser queimado não pode ser superior ao intervalo de $65 \%$ a $70 \%$.

$\mathrm{O}$ teor de umidade foi mensurado conforme o tempo de permanência, comumente empregado pela empresa, do resíduo no leito de secagem. Existem diversos fatores que interferem no tempo de permanência, tais como condições climáticas, a secagem ocorre a céu aberto e tanto maior a incidência de raios solar, menor a permanência. Outro fator é a demanda do setor, por vezes o aumento de demanda reduz o tempo de permanência. Mas, em média, a borra permanece no leito de secagem por cerca de 1,5 dias.

\subsection{Densidade}

Na Tabela 2 são apresentados os resultados dos ensaios de densidade da borra. A análise de densidade foi realizada a fim de descobrir a quantidade de borra produzida diariamente.

Tabela 2: Resultados da análise de densidade. Fonte: autores.

\begin{tabular}{ccc}
\hline $\begin{array}{c}\text { Densidade } \\
\left(\mathbf{g} / \mathbf{c m}^{\mathbf{3}}\right)\end{array}$ & $\begin{array}{c}\text { Média } \\
\left(\mathbf{g} / \mathbf{c m}^{\mathbf{3}}\right)\end{array}$ & $\begin{array}{c}\text { Desvio } \\
\text { Padrão }\end{array}$ \\
\cline { 1 - 1 } \multicolumn{1}{c|}{1,06} & & \\
\cline { 1 - 1 } 1,06 & & \\
\cline { 1 - 1 } 1,07 & 0,03 \\
\cline { 1 - 1 } 1,06 & & \\
\hline
\end{tabular}

A empresa produz uma caixa, no leito de secagem, por dia. Cada caixa tem 4,96 $\mathrm{m}$ de largura, 6,0 $\mathrm{m}$ de comprimento e $0,18 \mathrm{~m}$ de profundidade, logo cada leito armazena $5,3568 \mathrm{~m}^{3}$ ou 5.356,8 L/dia. Considerando a densidade média, $1,07 \mathrm{~g} / \mathrm{cm} 3$, então a geração diária de borra é de $5.732 \mathrm{~kg}$, ou seja, em um mês a Bioóleo gera $171.960 \mathrm{~kg}$ de borra.

Conforme discutido anteriormente, a densidade ideal para a queima em caldeira industrial varia de 0,65 a $0,80 \mathrm{~g} / \mathrm{cm} 3$ (VALE; BRASIL; LEÃO, 2014), logo a borra apresenta um densidade desfavorável ao processo de queima.

\subsection{Poder Calorífico}

O laudo do Centro de Qualidade Analítica indica que o poder calorífico inferior da borra é de $2.088 \mathrm{kcal} / \mathrm{Kg}$. A empresa produz $5.732 \mathrm{~kg} /$ dia de borra. Em calorias, a quantidade de energia que pode ser gerada é de 11.968.416 kcal/dia. Em um mês de queima da borra podem ser gerados $359.052 .480 \mathrm{kcal}$.

Considerando que o poder calorífico inferior do cavaco de eucalipto é $3.854 \mathrm{kcal} / \mathrm{kg}$ (QUIRINO et al. 2005), então as $359.052 .480 \mathrm{kcal} / \mathrm{mês}$ equivalem a 93.163,60 kg de cavaco de eucalipto.

Considerando o valor do cavaco de eucalipto 110,23 $\mathrm{R} \$ / \mathrm{kg}$, então a economia gerada pode ser de $21.427,63$ $\mathrm{R} \$ /$ mês. É importante destacar que essa energia térmica gerada é função da umidade da borra, 64,93\%. Caso a empresa adote um mecanismo para reduzir a umidade, área de secagem ao sol, a energia gerada pode ser maior. Consequentemente, o valor agregado também será maior.

Comparando a borra com outros resíduos já tradicionalmente utilizados na produção de energia térmica, é

\footnotetext{
${ }^{1}$ Valor referente ao $\mathrm{kg}$ de cavaco de eucalipto praticado em outubro de 2015, em compra realizada pela empresa.
} 

SOLUÇÃO ENERGÉTICA SUSTENTÁVEL

possível observar, na Figura 1, que o poder calorífico inferior da borra é similar ao de outros resíduos.

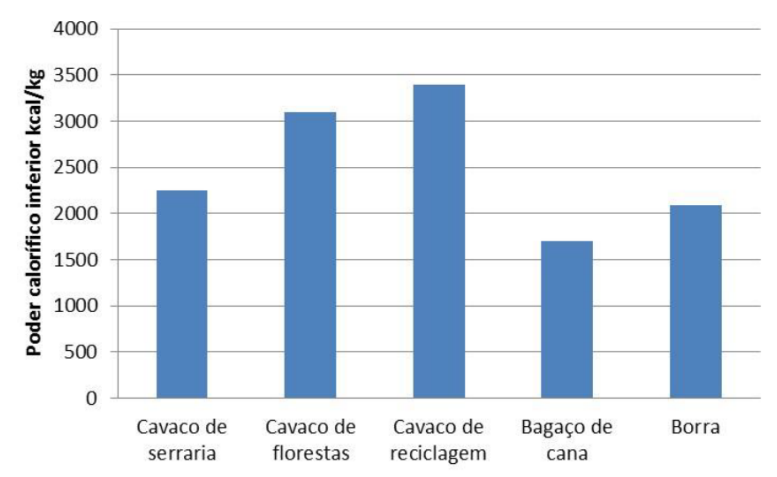

Figura 1: Poder calorífico inferior médio de diferentes materiais. Dados coletados do site opção verde, exceto o poder calorífico da borra.

Com base nos dados anteriores, pode-se afirmar que a borra é um combustível com poder calorífico similar a diversos resíduos de biomassa aos quais já são empregados como biocombustíveis, reforçando o potencial de emprego do resíduo como material combustível em substituição ao descarte.

O poder calorífico inferior da borra é similar ao que Silva e Morais (2013) observaram em relação ao bagaço de cana-de-açúcar. Portanto, a borra é um resíduo de baixo custo para a empresa e é uma alternativa viável para produzir energia limpa. É importante destacar que com o advento dos biocombustíveis, derivados de oleaginosas, tende a aumentar a produção deste resíduo. Além disto, a queima de combustíveis fósseis aumenta o teor de $\mathrm{CO}_{2}$ na atmosfera e este fenômeno não é cíclico. A queima da borra também emite gás carbônico, entretanto esse gás é absorvido durante o crescimento do vegetal que produz a semente onde serão extraídos os óleos, num processo cíclico e sustentável.

A caldeira da empresa consome $5.000 \mathrm{~kg}$ de cavaco de eucalipto por hora. Isso equivale a um consumo médio de 19.270.000 kcal/h. O resíduo gerado pela empresa durante um mês $(171.960 \mathrm{~kg})$ pode alimentar a caldeira por 18,63 horas.

\subsection{Cinzas}

O teor de cinzas (matéria mineral) é a fração que permanece como resíduo após a combustão do material, geralmente sólidos. Ela varia muito a depender do estado físico, espécie, da quantidade de amostra e da presença de solo na amostra.

Após a queima, o teor de cinzas na borra é apresentado na Tabela 3 .
Tabela 3: Resultados da análise de cinzas. Fonte: autores.

\begin{tabular}{ccc}
\hline $\begin{array}{c}\text { Cinzas } \\
(\%)\end{array}$ & $\begin{array}{c}\text { Média } \\
(\%)\end{array}$ & $\begin{array}{c}\text { Desvio } \\
\text { Padrão }\end{array}$ \\
\hline 9,38 & & \\
9,19 & & \\
9,11 & 9,29 & 0,18 \\
9,56 & & \\
9,19 & & \\
\hline
\end{tabular}

Os resultados encontrados apontam, em média, um valor superior $(9,29 \%)$ àqueles encontrados por Fré e Marcílio (2009) quando avaliaram o teor de cinzas após a combustão da borra de neutralização do óleo de soja. No trabalho, os autores apontaram um teor de cinzas igual a $4,80 \%$.

Pereira et al. (2000), indicaram que o teor de cinzas da madeira extraída do cavaco de eucalipto e apontaram uma variação de $0,5 \%$ a mais de $5 \%$. O teor de cinzas da borra, 9,29\%, é maior do que os teores de materiais comumente empregado na queima ou de outras borras. Tal fenômeno pode ser explicado pela existência de considerável presença de areia na amostra, oriunda do leito de secagem do resíduo.

A queima total da borra gerada diariamente resulta na produção $532,5 \mathrm{~kg}$ de cinzas. Ao final de um mês, será gerado $15.975,084 \mathrm{~kg}$ de cinza.

\section{6 Ácidos graxos totais (AGT)}

A análise para determinação de ácidos graxos totais na borra foi realizada com base em procedimentos de análise documentados pela empresa. Os resultados das análises podem ser observados conforme a Tabela 4 .

Tabela 4: Resultados da análise de cinzas. Fonte: autores.

\begin{tabular}{ccc}
\hline $\begin{array}{c}\text { AGT } \\
(\mathbf{\%})\end{array}$ & $\begin{array}{c}\text { Média } \\
\text { (\%) }\end{array}$ & $\begin{array}{c}\text { Desvio } \\
\text { Padrão }\end{array}$ \\
\hline 21,74 & & \\
23,00 & & \\
21,52 & 22,22 & 0,70 \\
\hline 22,62 & & \\
\hline
\end{tabular}

Esse teor de ácido graxo total é favorável a combustão. Visto que as gorduras, em geral, possuem boa qualidade de queima. Esse resultado é equivalente ao encontrado por Fré e Marcílio (2009) quando determinou a concentração de ácido graxo total $(27,6 \%)$ na acidulação da borra de neutralização de óleo de soja.

A empresa produz $5.732 \mathrm{~kg}$ de borra/dia com um percentual de AGT de 22,22\%, isto equivale a perda 
VIABILIDADE DE QUEIMA DE RESÍDUO DE MAMONA: UM PROBLEMA INDUSTRIAL VIRA METODOLOGIA DE ENSINO E SOLUÇÃO ENERGÉTICA SUSTENTÁVEL

de $1.273,65 \mathrm{~kg}$ de gordura/dia. Ou seja, em um mês são descartados $38.209,51 \mathrm{~kg}$ de ácidos graxos. Cabe destacar que estes ácidos graxos são residuais porque o método de extração não permite retirá-lo completamente. Consequentemente, há um desperdício de óleo que pode ser aproveitado durante a combustão do resíduo para gerar energia térmica.

\subsection{Aspectos educacionais}

A interação entre o problema, ação de mediação docente, enfretamento do problema pelos aprendizes e solução final resulta na construção de saberes que extrapolam os limites da disciplinaridade escolar. Pois a criação de solução de um problema real não "cabe" numa ou outra disciplina, mas na interação dos saberes correlatos ao problema. A presença de um problema real, em substituição ao problema de papel, motiva os discentes e cria o contexto para aprender gestão de projetos, técnicas de realização de ensaio, técnicas de apresentação de um produto ou solução aos gestores da empresa além da apropriação significativa dos saberes à medida que estes não apenas estão sendo memorizados para resolver uma prova, ou algo similar. Mas, tais saberes se relacionam com outros saberes e com o problema concreto, operacionalizando a aprendizagem significativen 2 Para Moreira (2016), a "aprendizagem significativa é o mecanismo humano, por excelência, para adquirir e armazenar a vasta quantidade de ideias e informações representadas em qualquer campo de conhecimento" (p.1).

\section{CONSIDERAÇÕES FINAIS}

Os ensaios de caracterização do material apontam a viabilidade de aproveitamento da borra como combustível.

As análises de AGT (Ácidos Graxos Totais) revelaram que o material tem um alto índice de ácidos graxos, o que contribui positivamente para uma boa qualidade de queima do material.

\section{REFERÊNCIAS}

ABNT. NBR 11941: Madeira - Determinação da densidade básica. Rio de Janeiro: ABNT - Associação Brasileira de Normas Técnicas, 2003. 6 p.

NBR ISO/IEC 17025: requisitos gerais para a competência de laboratórios de ensaio e calibração. Rio de Janeiro: ABNT - Associação Brasileira de Normas Técnicas, 2005. 31 p.

\footnotetext{
${ }^{2}$ Segundo Moreira (2016) a "aprendizagem significativa é o processo através do qual uma nova informação (um novo conhecimento) se relaciona de maneira não arbitrária e substantiva (não - literal) à estrutura cognitiva do aprendiz".
}

ACOS. Ba 2a-38. USA: AOCS - American Oil

Chemists Society, 2009. Moisture and Volatile Matter.

CAETANO, L.; DUARTE JUNIOR, L. A. Estudo comparativo da queima de Óleo B.P.F. e de lenha em caldeiras - estudo de caso. In: ABCM (Ed.). Anais do XI CREEM. Nova Friburgo: , 2004. Disponível em: $<$ http://www.abcm.org.br/app/webroot/anais/creem/ 2004/TE/CRE04-TE01.pdf>, Acesso em: 24 jul. 2013.

FRÉ, N. C. da; MARCíLIO, N. R. Obtenção de Ácidos graxos a partir da acidulação de borra de neutralização de Óleo de soja. In: UNIVERSIDADE FEDERAL DO RIO GRANDE DO SUL. Anais do VIII Oktoberforum - Ppgeq: Seminário do programa de Pós Graduação em Engenharia Química. 2009. p. 20 - 23.

FREIRE, P. Pedagogia da Autonomia. São Paulo: Editora Paz e Terra, 1996. 6 p.

GARCIA, R. Combustíveis e combustão industrial. Rio de Janeiro: Interciência, 2002.

KRAUSE, D.; EYERER, P. Shulerprojekte managen: TheoPrax methodik in ausund weiterbildung. Bielefeld: W. Bertelsmann Verlag, 2008.

MOREIRA, M. A. Aprendizagem significativa: Um conceito subjacente. 2004. Disponível em: <http://www.if.ufrgs.br/ moreira/apsigsubport.pdf> Acesso em: 23 mar. 2016.

OPÇÃO-VERDE. Opção verde resíduos florestais. Bioenergia de pinus e eucalipto: lenha-cavaco-serragem. 2014. Disponível em: <http://www.opcaoverde.com.br/residuosflorestais/> Acesso em: 10 set. 2014.

PEREIRA, J. C. D.; STURION, J. A.; HIGA, A. R.; HIGA, R. C. V.; SHIMIZU, J. Y. Características da madeira de algumas espécies de eucalipto plantadas no Brasil. Colombo: Embrapa Florestas, 2000.

PERRENOUD, P. Construir as competências desde a escola. Porto Alegre: Artmed, 1999. Trad. Bruno Charles Magne.

QUIRINO, W. F.; VALE, A.; ANDRADE, A.; ABREU, V. L. S.; AZEVEDO, A. d. S. Poder calorífico da madeira e de materiais ligno-celulósicos. Revista da Madeira, v. 89, p. 100-106, 2005.

SILVA, M. B. da; MORAIS, A. dos S. Avaliação energética do bagaço de cana em diferentes níveis de umidade e graus de compactação. In: Anais do XXVIII Encontro Nacional de Engenharia de Produção. 
Rio de Janeiro: ABEPRO, 2008. Disponível em: $<$ http://www.abepro.org.br/biblioteca/enegep2008_tn_ stp_077_543_11289.pdf>.

SPENCE, R.; MULLIGAN, H. Sustainable development and the construction industry. Habitat international, Elsevier, v. 19, n. 3, p. 279-292, 1995.

VALE, A. T. d.; MENDES, R. M.; AMORIM, M. R. S.; DANTAS, V. F. d. S. Potencial energético da biomassa e carvão vegetal do epicarpo e da torta de pinhão manso (Jatropha curcas). CERNE, scielo, v. 17, p. 267 - 273, 06 2011. ISSN 0104-7760. Disponível em: <http://www.scielo.br/scielo.php?script=sci_ arttext\&pid=S0104-77602011000200015\&nrm=iso >

VALE, A. T. do; BRASIL, M. A. M.; LEÃO, A. L. Quantificação e caracterização energética da madeira e casca de espécies do cerrado. Ciência Florestal, v. 12, n. 1 , p. 71-80, 2005. 